\title{
Performing walking Sims: from Dear Esther to Inchcolm Project
}

Mona Bozdog

Dayna Galloway

(C) Mona Bozdog \& Dayna Galloway, 2020

The definitive, peer reviewed and edited version of this article is published in Journal of Gaming and Virtual Worlds 12(1): pp. 23-47, 2020 DOI: https://doi.org/10.1386/jgvw_00003_1 


\title{
Title
}

Performing Walking Sims - From Dear Esther to Inchcolm Project

\begin{abstract}
In 2012 The Chinese Room launched Dear Esther, a video game which would go on to shape video game history and define a new genre: the walking simulator. Walking simulators renounce traditional game tropes and foreground walking as an aesthetic and as a dramaturgical practice which engages the walker/player in critical acts of reading, challenging and/or performing a landscape.

In October 2016, Dear Esther was adapted as a site-responsive, promenade performance set on the Scottish island of Inchcolm in the Firth of Forth. The resulting performance, Dear Rachel, was then experienced alongside the game under the umbrella name Inchcolm Project. This hybrid event - multi-media (promenade performance, gameplay, musical performance) and mixed-reality (with physical, augmented and virtual components) required the development and implementation of complex processes of remediation and adaptation. Drawing from theoretical landscape and practitioner reflection, this paper puts forward a design framework - storywalking - which reconciled the two adaptation challenges: responding to the site, and to the game.
\end{abstract}

\section{Keywords}

Walking, performance, walking simulators, promenade performance, adaptation, sitespecific, re-mediation, game design

\section{Introduction}

Dear Esther (The Chinese Room, 2012) strands the player in a virtual representation/interpretation of Boreray (in the Scottish St Kilda Archipelago) to explore its histories and legends, and uncover the story behind its enigmatic narrator. As the player walks around the island towards the red blinking light of the aerial, they trigger snippets of VO narration and encounter moments of environmental storytelling.

In October 2016, the authors adapted this video game into a site-responsive, promenade performance set on the Scottish island of Inchcolm in the Firth of Forth. In Inchcolm Project we designed a site-responsive and game-responsive performance which celebrated walking as a critical and dramaturgical practice and site as an active component of meaning.

Inchcolm Project consisted of a two-hour experience on Inchcolm island and it had three parts: a promenade performance adapted from Dear Esther called Dear Rachel, a gameplay projection (Dear Esther played live and projected onto a wall in Inchcolm Abbey), and a final musical performance (Mantra Collective performing the game's soundtrack). The audience/players journeyed on Inchcolm and in Dear Esther in search for meaning. As they explored the island, the Sonic Maps app running on their phones ${ }^{1}$ triggered one of the 22

\footnotetext{
${ }^{1}$ Sonic Maps was a free application (no longer available) developed by Recursive Arts. It consisted of two associated apps, an editor in which projects were created by geo-tagging audio to the chosen locations, and a
} 
geo-tagged audio files. They could also discover visual installations and/or musicians who were located in specific locations around the island.

Developing Inchcolm Project involved complex processes of adaptation (of a game and to a site) and dramaturgy (of assemblage and (syn)aesthetics), which shaped the design strategies, techniques and tools deployed in its making. The hybrid nature of the project, having live and virtual components, demanded that we develop interdisciplinary working methods, borrowing from both game design and performance practice (for a detailed discussion see Author 1, 2019).

In what follows we will reflect on the design process of Inchcolm Project to emphasise some of the unique opportunities afforded by adapting a walking sim into a live performance. We will first introduce walking simulators to better understand what makes them a fertile ground for exploration. We then discuss the design of Dear Esther and how its design strategies and techniques shift and mutate when implemented in a physical environment. Finally, we propose a design framework developed through practice which reconciles the two adaptation challenges, of the game and to the site, by focusing on the moving body. We call this framework 'storywalking' as it foregrounds the richness of walking as simultaneously performing and playing an environment. This framework was a result of developing and reflecting on Inchcolm Project and draws from site-specific performance and game design methods.

\section{Walking Sims - foregrounding walking as an aesthetic, dramaturgic and critical practice}

The term 'Walking simulators' or 'walking sims' started gaining currency in 2012 when The Chinese Room launched Dear Esther, a video game in which the player explores a deserted Hebridean island in search of an explanation for why they are there. Despite some notable precursors to the genre (Myst, Cyan, 1993), the first walking sim is considered to be Dear Esther.

Walking simulators are a subgenre of first-person, exploration video games which "offer an experience of spatial storytelling and exploration, in which players wander around a narratively-rich environment without earning points or necessarily accomplishing tasks" (Kagen, 2018). Their perceived lack of 'traditional' gameplay led frustrated players to coin the (intended) derogatory name 'walking simulators'. This frustration was directed toward the alternative style of gameplay: renouncing traditional objectives, challenges and rewards, opting for simpler interaction schemes and less in-game actions, and emphasising narrative and sensory-driven experiences. In walking sims, the player primarily walks. This demands little concentration and dexterity from the player allowing them to focus instead on the aesthetic, narrative and sensory aspects of gameplay (see Calleja's 'Player Involvement Model', 2011, or Upton's discussion of interpretive play, 2015). This minimal interaction design requires little previous gaming experience which makes them accessible to a diverse player community, while at the same time encouraging designers to experiment with the

player that audiences could download onto their phones and track their location to play the audio.

http://sonicmaps.org/ 
form and creatively explore alternative mechanics, visual storytelling, lighting, music and sound design to create atmosphere and convey the narrative (Bozdog and Galloway, 2019).

Movement in walking sims is purposefully slow as to allow the time for the story, music, sound, and environment to be taken in. Dan Pinchbeck, Dear Esther's designer, argues that the lack of gameplay complexity can be replaced with experiential (narrative, interpretive, emotional, sensory, aesthetic) complexity. He argues that "lack of stimulation is not lack of experience", on the contrary "lack of stimulation allows different kinds of reflective, emotional experiences. We have to provide space and time for different types of experiences and different types of resonances to flourish" (Pinchbeck, 2012a). Walking sims allow the players the time to explore and experience the gameworld at their own pace (Kagen, 2017; 2018; Ruberg, 2019; Bozdog and Galloway, 2019).

Furthermore, 'walking simulator' loses all negative connotations if one considers and embraces the richness and complexity of the practice(s) of walking. Virtual walking, like its physical counterpart, unlocks narratives, thoughts, emotions, memories and imagination, and it allows space for meditation by setting up a slower pace. The walk becomes a journey, inviting contemplation, introspection, memory and meditation. As Rebecca Solnit observed "While walking, the body and the mind can work together, so that thinking becomes almost a physical, rhythmic act... is a state in which the mind, the body, and the world are aligned" (Solnit, 2002: xv). When walking through an environment we take it all in, and as the landscape unfolds so do thoughts, memories, images and recollections of places and walks past. Solnit emphasizes the role of walking as a visual activity which is made possible by the slow pace of walking, or as she calls it, a leisurely tour. As Solnit observes, walking is pleasurable in and of itself, both a cognitive and aesthetic experience, a rhythm of movement which stimulates thinking, imagination and memory thus linking self and memory, body, mind and environment. These abilities of walking are (re-)created in walking sims through (virtual) walking which gains similar powers. In walking sims walking is embraced as "a mode of inquiry, a politics and an aesthetic practice" (Bassett, 2014: 399) as well as a dramaturgical practice which engages the walker/player in critical acts of reading, challenging and/or performing a landscape (Myers, 2010; Turner, 2004). We argue that due to their accessible and experimental nature alongside their emphasis on storytelling and walking as an aesthetic and (syn)aesthetic practice walking sims are a lucrative and fertile ground for exploration through performance.

\section{Performing Dear Esther}

Dear Esther strands the player on an uninhabited island (a virtual representation of Boreray in St Kilda Archipelago) to explore its histories, legends, and ghosts and discover the story behind its enigmatic narrator. As they walk around the island to reach the red blinking light of the aerial (radio mast) they trigger snippets of VO narration and encounter moments of environmental storytelling. Robert Briscoe, the lead artist on the project, describes the game as: 
a deep, poetic ghost story told using game technologies. You explore a deserted island, uncovering a tale of love, loss, grief and redemption, delivered through a stunning voiceover and soundtrack set against beautiful environments. Rather than traditional gameplay the focus is on exploration, uncovering the mysteries of the island and discovering who Esther is and why you're there. (Briscoe, 2012b)

The game unfolds as the player explores the desolate island. The world of Dear Esther is built around the intertwining of destinies and stories of various characters, Esther, the narrator, and Paul as well as two former inhabitants of the island: a hermit and shepherd called Jakobson, and finally a chronicler by the name of Donnelly. The narrative information is delivered through the VO narration and environmental storytelling - narrative elements that can be 'read' in the environment. The narrator introduces all the other characters, the player only knows what he tells them. However, the player can get a 'feeling' of who the characters are through music.

There are very few accounts of Dear Esther, if any, which do not mention its achievement in terms of music. Jessica Curry's score supports the emotional states of the game's protagonist, and creates the mood and tone of the island. The music accompanies the text and environment, like an emotional filter to the game, imbuing it with a "sense of loneliness and longing" (Curry, 2013). Curry opted for a "sparse and spare" style of playing which she characterises as Scottish (ibid.) for most of the tracks which play on the island (except the underground caves) to communicate the desolation of the island, its hostile and unwelcoming nature, its harshness to human life. For Curry, the music is the voice of the island and of the absent characters (Pinchbeck et al., 2017), it stands in for the non-present and voiceless entities, sometimes complementing and sometimes subverting the narrator's voice.

The game's environment is haunting and beautiful, narrative and sensorially rich, evocative and symbolically charged thus illustrating Fiona Wilkie's functions of the site in site-specific work: symbol, storyteller and structure" (Wilkie, 2002: 158). To focus the player's attention on the environment and the narrative, the designers have stripped down the game's mechanics to a bare minimum: the only permitted in-game actions are walking, (limited) swimming, zooming-in, and looking around. The impossibility to interact with the objects or manipulate them supports an interpretation of the island as a liminal space, a 'Purgatory' of sorts where the character must confront and accept his own past in order to achieve absolution and redemption. An island-as-purgatory interpretation is also supported by the inability to escape the island, for example, if the player tries to swim away from the island (or falls to their 'death') a voice prompts them to "Come back" and the player respawns on the shore. The player cannot change or escape the island in any way because perhaps the island is not real, the player-character is not real, or both.

As the player makes their way around the island they listen to the character as he relives painful memories in an infinite loop. The character's aspiration for salvation or redemption comes into conflict with a cold and unflinching environment. Dear Esther can be read as an attempt at salvation through a walk of absolution. The four chapters of the game: The Lighthouse, The Buoy, The Caves, and The Beacon are distinct areas on the island and mirror the character's internal journey. The initial solitary guilt, isolation, and breaking down of the 
physical body are mirrored in the decaying and decrepit structures on the island and the desolate landscape. The character's descent into the subconscious to face the traumatic event which brought him on the island is illustrated by the descent into the visually-surreal caves. And the character's final ascent is mirrored by the climb toward the aerial, the jump and the flight. As the character approaches his end, he starts using increasingly more religious references, associations and imagery. Is he (re-) discovering his faith as he nears his demise? Ambiguity is not just present in the writing but also in character creation. There is no way of knowing whether the island and the other characters are real or a result of the narrator's fevered imagination.

To adapt the game, we first wanted to really understand how it efficiently and successfully delivers a meaningful aesthetic experience. From the above overview it already becomes clear that Dear Esther manages to do so through a combination of environment, narrative, sound and interaction design. These were the four pillars of our adaptation process and we will discuss each of these in turn particularly in relation to their 'translation' into physical design. The game served as an initial 'text' that has been reworked, reshaped and rewritten. As Hutcheon and O'Flynn's argue, adaptation is not only a process of transposing a work into another medium, frame or genre but is also an active process of re-interpretation, and re-creation (2012). Dear Rachel is evocative of Dear Esther while at the same time distinct.

\section{Performing Inchcolm Project: site- and game-responsive design}

In adapting Dear Esther, we wanted to build on its design, while at the same time to create a new piece of site-responsive work. The motivation behind this was two-fold, we wanted to emphasise how Dear Esther is relevant for exploring current humanitarian concerns while in the same time exploring how we could use the theme of guilt (at individual level in the case of Dear Esther and societal level - Dear Rachel) to connect the performance and the game. This required a process of selection and addition: selecting some of the game's design strategies and developing new ones which arose from the necessities of working with the site and live performance.

The feeling of isolation, loneliness, and panic are supported by the fact that the player is stranded on a small and unfriendly piece of land surrounded by water. There is no way out unless she manages to unlock its secret. We wanted to instil the same feelings in the audience while at the same time to take advantage of all the new sensations facilitated by the body being and moving on a Scottish island in mid-October. The smells, textures, temperature, sounds, tastes, light and landscapes on Inchcolm island were accessed through performance. The most important design choice that we made was that regardless of how we would structurally adapt the game, the setting must be an island. The island in Dear Esther was the central part of our experience and shaped all of the others

We wanted to deconstruct Dear Esther to understand how its design elements collaborated to create a strong and lasting emotional experience. This involved a process of reverse engineering its design, going behind the gameplay experience to analyse the design strategies which underpinned its visual style and environments, its narrative, sound and 
interaction design. These design strategies were then adapted to Inchcolm island, filtered through its narrative, sensory, structural and symbolic presence.

The visual design combined environmental design strategies originating in Dear Esther with the site-specific constraints and opportunities afforded by Inchcolm island with the aim of emphasising the site's potential to become "an active component in the creation of performative meaning, rather than a neutral space of exposition" (Pearson, 2010: 36). Applying the design lessons learned from Dear Esther we wanted the environment to reflect the story, to amplify its emotional potential and to anchor the story in the audience/players' embodied experience.

Throughout the design process of Inchcolm Project we engaged with Robert Briscoe's design strategies (developed in Dear Esther) to shape the environment as an emotional and narrative landscape (2012a). His use of macro and micro details, the subliminal signposting and the use of dramatic elements to frame and set an emotional and narrative scene, were adapted in Inchcolm Project for a living body moving through a living and breathing island.
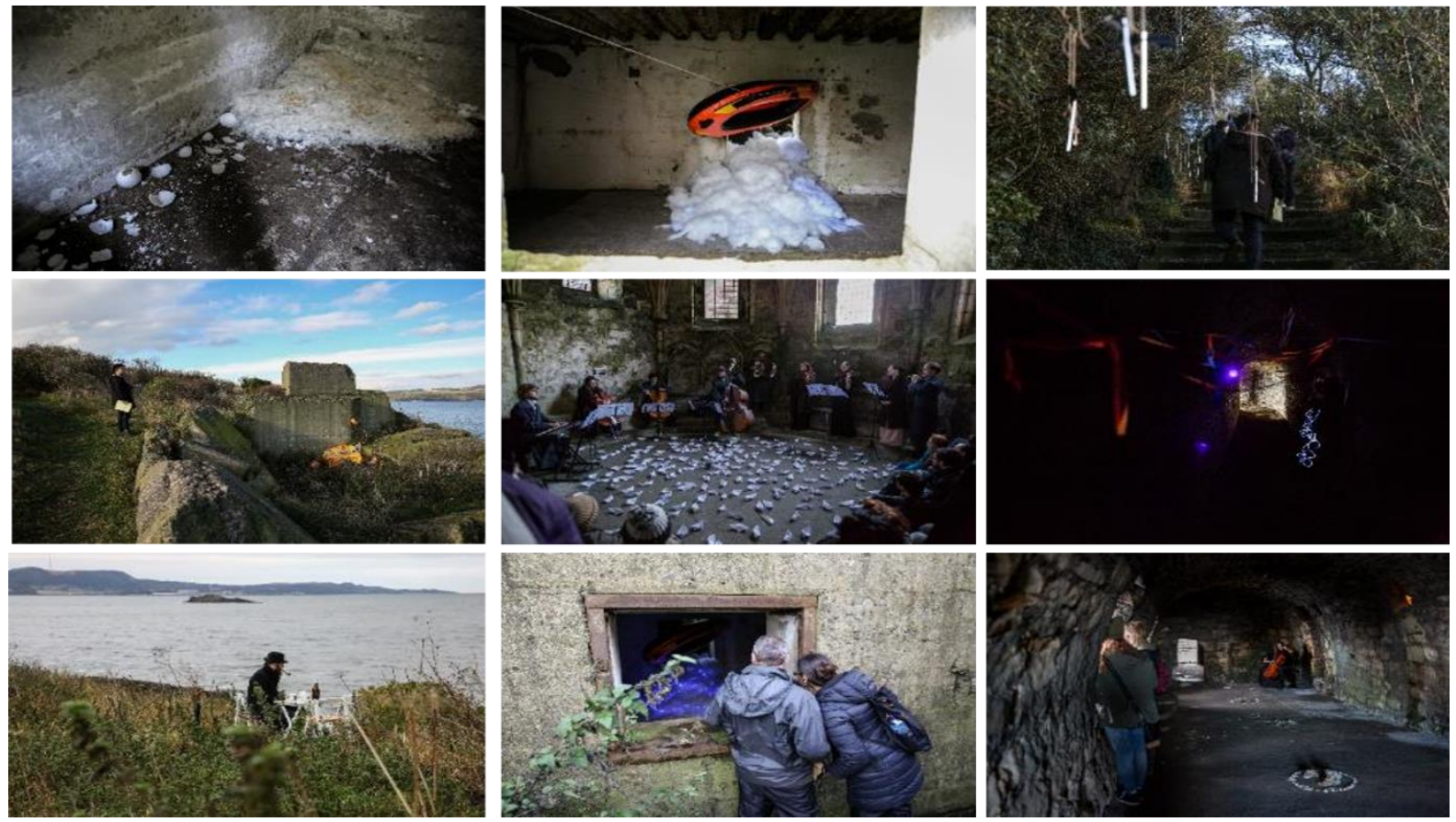

Figure 1 Installations in Inchcolm Project

Additionally, Inchcolm Project is site-responsive and was utterly shaped by Inchcolm Island, at a structural, sensory and narrative level: its affordances and limitations impacted on the design. The island 'dictated' how the performance was structured, how we worked with sound, where the installations and sounds were positioned, the duration and date of the performance, the routes and paths that could be explored so on. The island's sensory potential was also emphasised: the smells, the sounds, the moods, the colours and the textures, the light and temperature shaped the performance.

The design of a dramatic visual style in Inchcolm Project revolved around framing rather than creation, focusing the audience/players' attention on the dramatic landscape rather than creating it (as in the case of Dear Esther). This was achieved by tagging the audio files and positioning the installations and musicians in aesthetically and dramaturgically 
meaning-full locations which drew attention to and emphasised the island's environments and narratives. The audio file locations opened up vistas and panoramas offering views of the Firth, the shores or the island itself. They exposed the island in the changing light of late afternoon and the constantly changing cloud patterns (see Figure 2). The musicians and installations were hosted either inside dilapidated military barracks or the Abbey. These spaces told the stories of the island's previous uses and inhabitants (see Figure 3).

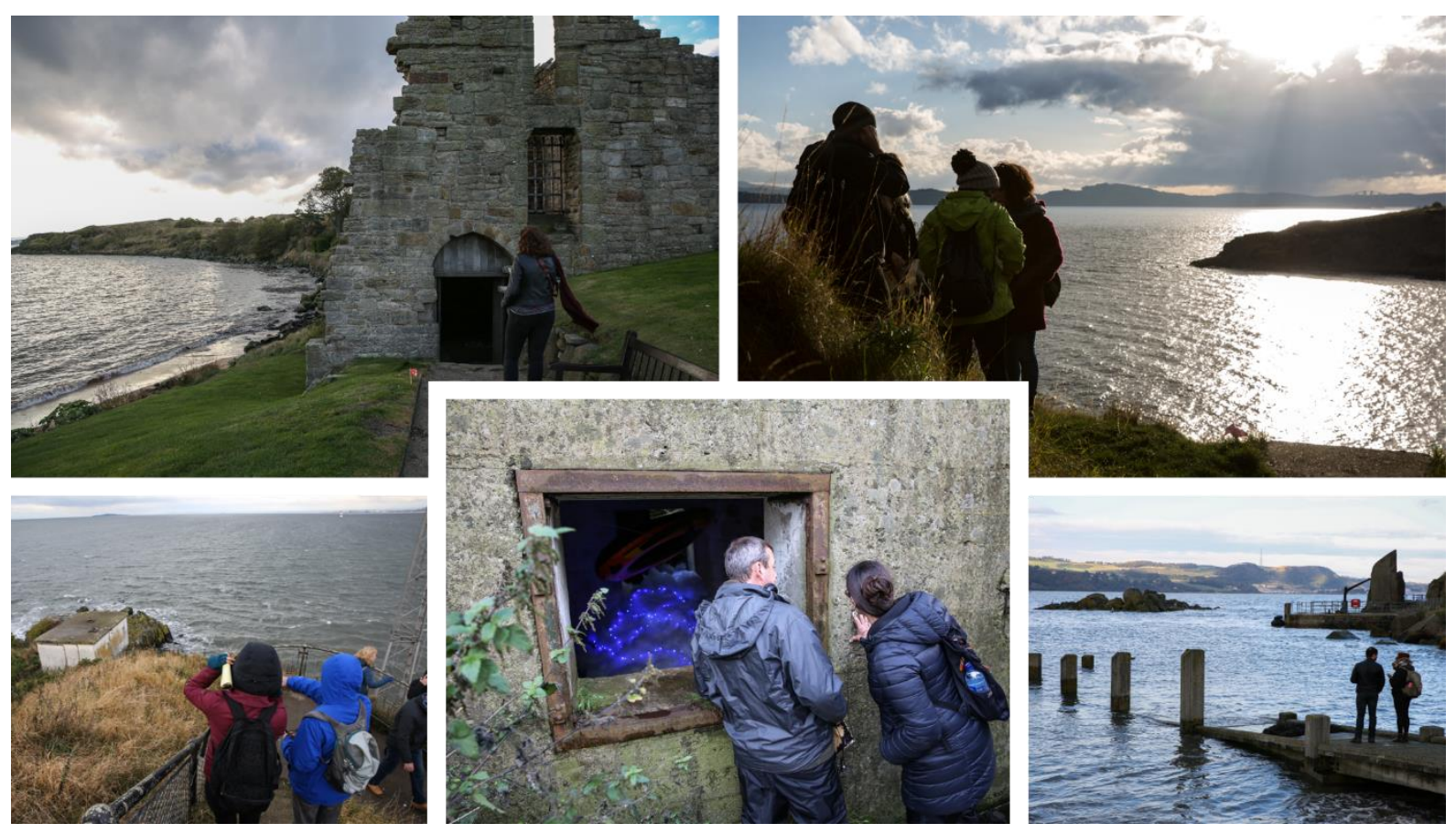

Figure 2 Dramatic emergent landscapes in Inchcolm Project
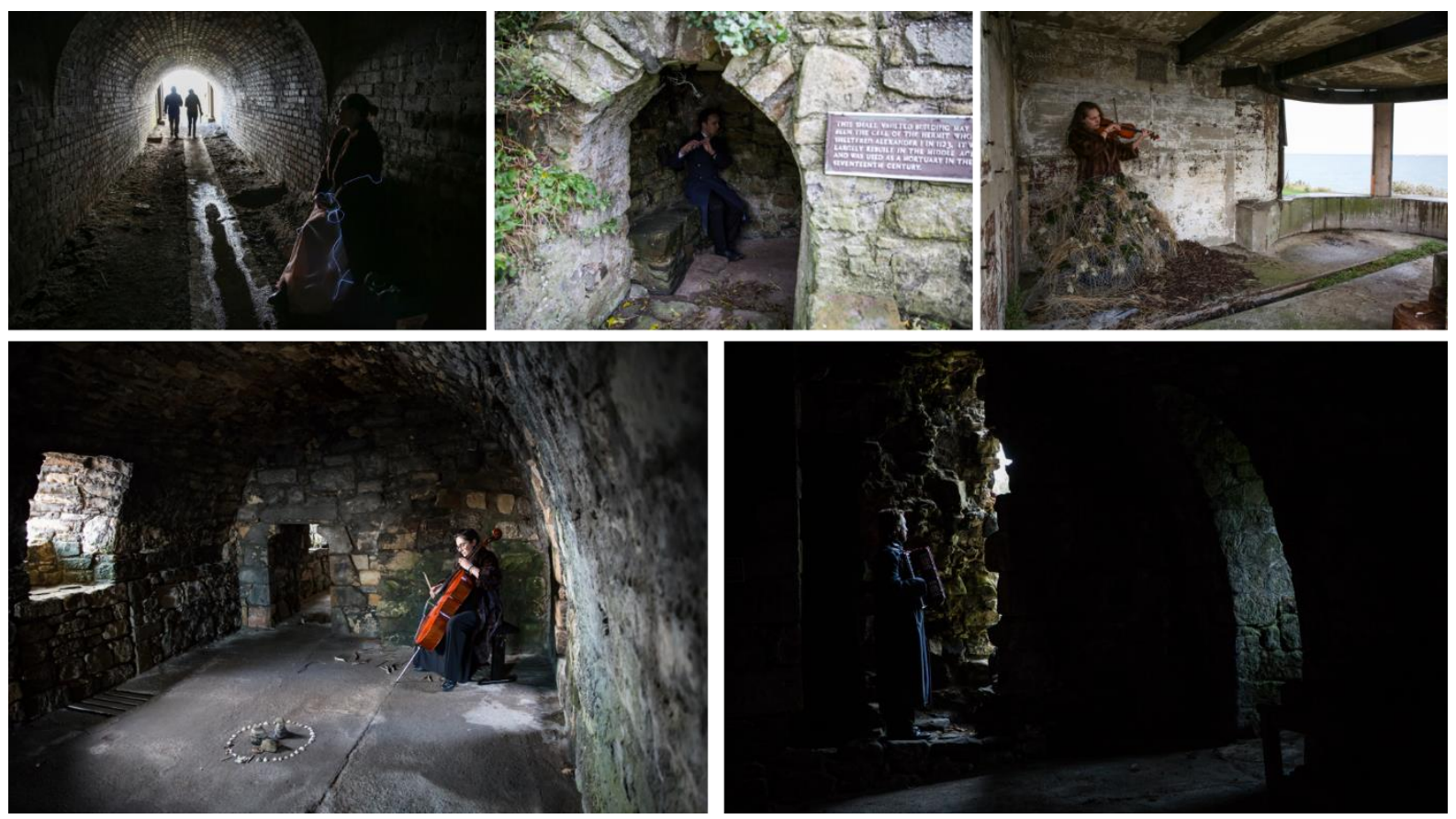

Figure 3 Musicians in Inchcolm Project 
The installations invited the audience/player to pay attention to the narrative details embedded in the environment while the panoramic vistas invited them to contemplate the emergent, ever-changing mood of the island. Alternating between them they could start to assemble a narrative from the dramatic landscape and the micro-tableaux of environmental storytelling, what I referred to earlier in relation to Briscoe's work as play with perspective. Patterns emerged from the combination of the designed, natural and human elements. The audience/players were constantly on the move, scattered around the island, standing still on edges and shores, looking out at sea, ghostly and silent, which led to unexpected encounters and emergent landscapes. They were an active part of the landscape, contributing to each other's narratives.

The elements of environmental storytelling, similar to Dear Esther, are designed to communicate the traumatic event which explains the presence of the character on the island. Furthermore, the bright colours on the island are all the marks of human life, the physical and psychological traces that the protagonist leaves on the island. This use of colour in Dear Esther gains symbolic and narrative significance because it acts as a visual manifestation of the memory of this traumatic event. The memory is projected onto the environment causing a dramaturgical conflict with the natural landscape: meaning becomes unstable when car parts, for example, start appearing on the island. This event is represented through recurring colours, displaced and misplaced objects, unnatural assemblages of natural and human-made materials. In Dear Esther, the island is gradually coated in fluorescent green writing, paint, car parts, emergency room paraphernalia, chemical symbols, ultrasound images alongside bird nests, broken eggs, feathers and bird bones. In Dear Rachel, Inchcolm is overgrown by parasitical fluorescent orange rubber and tape, dinghies, buoyancy aids, barbed wire, metallic wind chimes, fishing nets, life jackets, wire birds alongside bark, feathers, egg shells, twigs, shells and seaweed. In Dear Esther the fluorescent green of the accident starts taking over the island, while in Dear Rachel the orange of the refugee crisis bleeds over the environment (Figure 4).
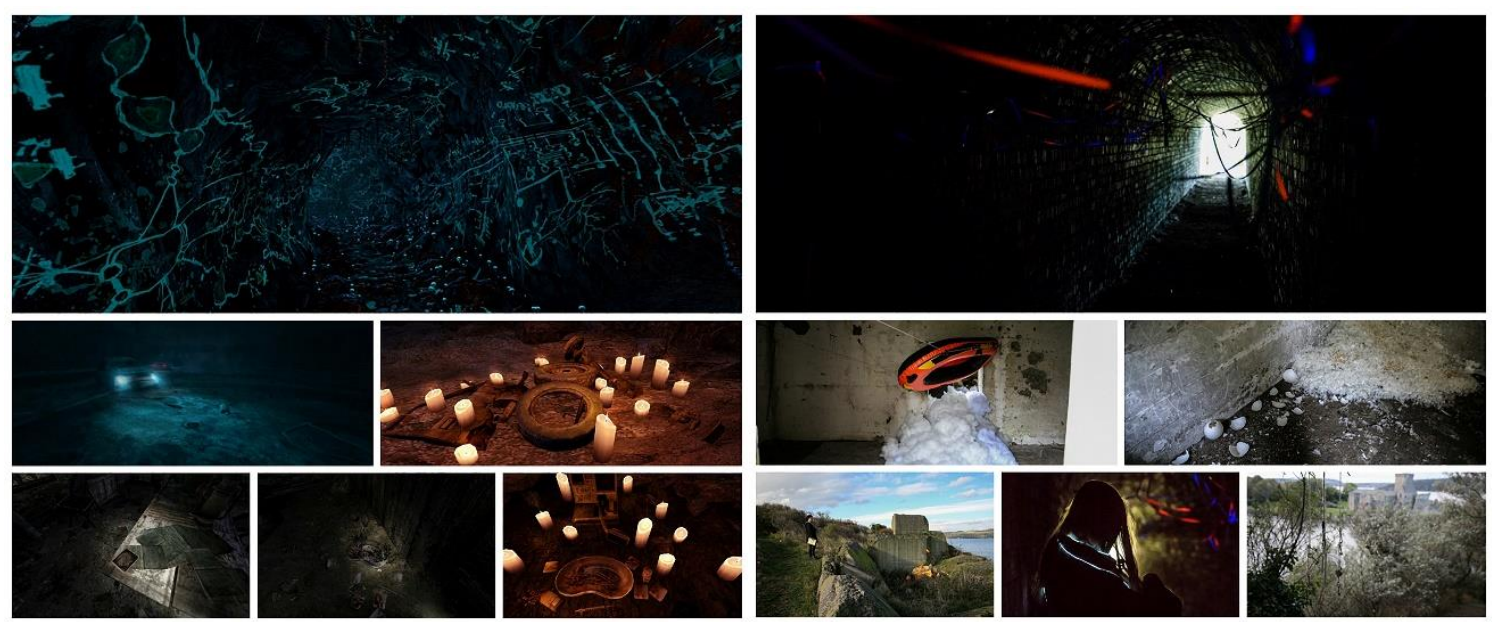

Figure 4 Symbolic use of colour in Dear Esther (left) and Dear Rachel (right)

In Inchcolm Project we engaged with a form of environmental storytelling called subliminal signposting (Briscoe, 2012a). Briscoe coined the term "subliminal signposting" to refer to how the environment can be used to "unconsciously guide the player through some of the 
more figurative aspects of the story not directly conveyed through the narrative" (2012a). Subliminal signposts, he argues, can be literal or symbolic. The literal way refers to how the environment is effectively a visual representation of the narrative, for example the voiceover refers to the bothy as the player sees a bothy atop a hill. This is different to how signposting has traditionally been used in games, to convey gameplay information to the player: either to help with navigation (visual landmarks), or to prepare for a battle/challenge (telegraphing, see Smith and Worch, 2010), or to hint at solutions (puzzle keys) so on. Subliminal symbolic signposting contributes to building an emotional connection to the story and the character because it visually represents states, feelings, memories and thoughts, it fulfils a dramaturgical rather than a ludic function. Briscoe used symbolical subliminal signposting largely in 'The Caves' where the visual style, the music, the sound and the narrative all break the conventions of realism and slip into a dream-like aesthetic (for a detailed discussion of subliminal signposting in Dear Esther see Briscoe, 2012a; Author 1, 2019).

In Inchcolm Project this was translated into 'The Tunnel' installation. The tunnel (Figure 5, right) was designed to fulfil the same dramaturgical function as the caves. Two musicians were stationed inside the tunnel (Luci Holland - vocals, during the first performance, Luisa Brown - violin, during the second, Figure 6). They were 'entangled' in El-wire (neon battery powered luminous wire) which made them shimmer slightly in the complete darkness of the tunnel. Orange and blue fluorescent tape was anchored from the tunnel ceiling. When illuminated by the audience/players with the black light torches handed to them at the entrance, the tape became visible, moving in the wind as the audience/players passed underneath. The colours, blue and orange intermingled, were illustrative of the traumatic incident that haunts the protagonist, the capsizing of the refugee boat and the orange life jacket sinking. Luci and Louisa were heard before they could be seen, the eerie voice or violin piercing through the darkness.

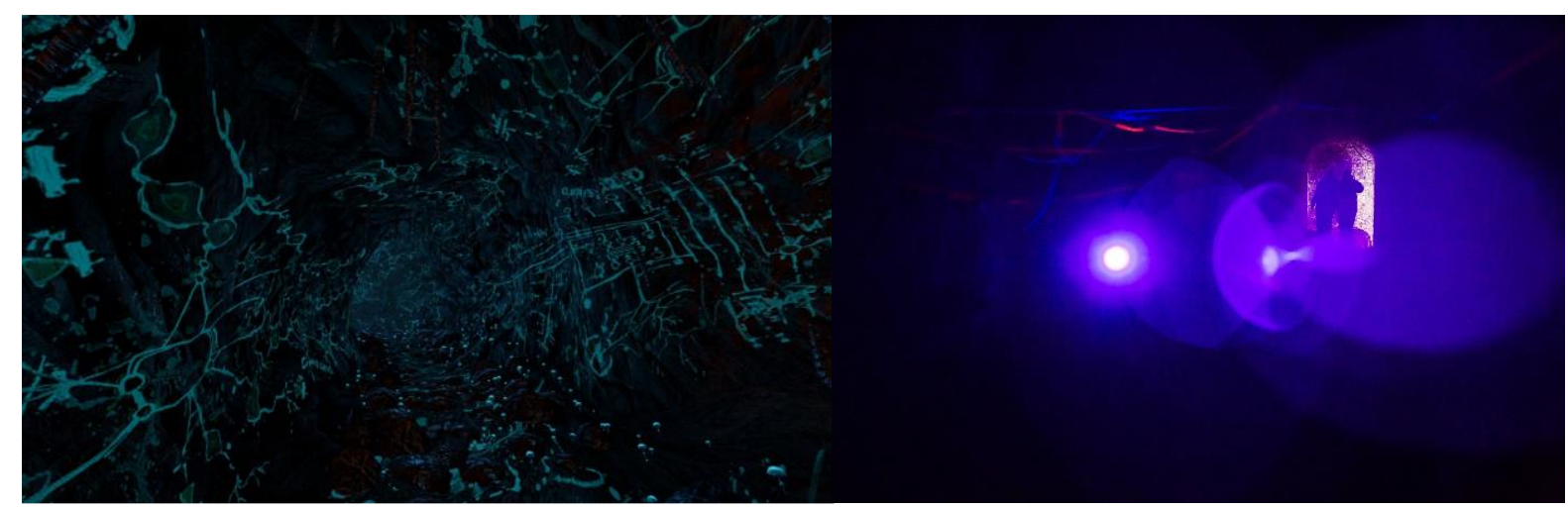

Figure 5 subliminal Signposting in Dear Esther (left) and Inchcolm Project (right) 


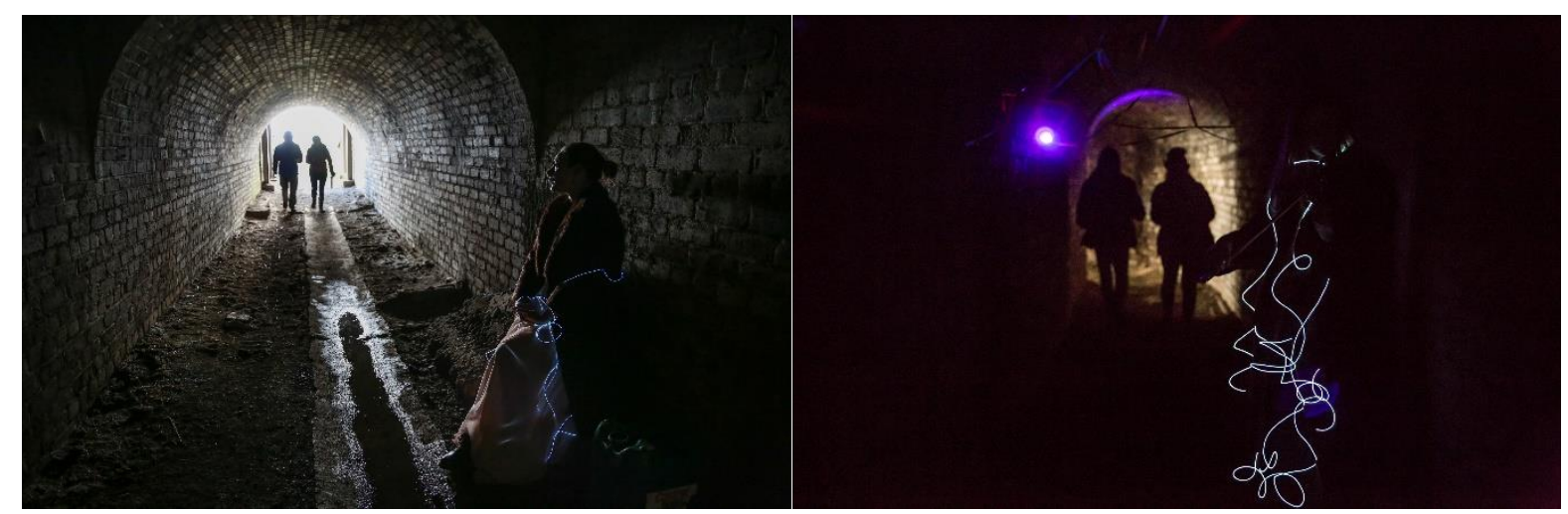

Figure 6 The musicians in the tunnel, Lucy - vocals (left), Louisa - violin (right)

The audio file that the audience/players heard at the entrance or exit from the tunnel, depending on their chosen route, described the process of drowning.

"Sometimes, if the limbs are short, the body comes out facing upwards.

And then the waves plant them on the shore.

Orange gas flowers blooming in the sand.

And started walking between the orange blossom away from the sirens that were drowning the goodbyes"

(Author 1, 2016)

The Tunnel illustrates symbolic subliminal signposting as it generates a feeling which is not literally referenced in the text, but which contributes to its interpretation.

The overarching symbolic power of the island was supported the visual micro-level by interactive and non-interactive installations that we called scenes and shrines. Scenes, similar to the stage in theatre, are activated in performance by the audience/players. This demands that the audience/players undergo an essential transformation from audience/player-witness to audience/player-protagonist ('percipients', Myers, 2010). The shrines, the non-interactive vignettes which work to convey additional information about the world, the character, or the traumatic event, are embedded in the environment. The protagonist in Dear Rachel has left traces in the environment for the audience/players to decode, just like the protagonist in Dear Esther has. In Inchcolm Project the traumatic event recurs in the environment through different symbolic images: the capsized boat, the pile of buoyancy aids, the unmarked graves, the broken eggs, the wire birds caught in the fishing nets, the candles, coupled with auditory cues, either VO or live music, which support them in conveying emotion. These were incorporated in the three scenes (the tree-tunnel [1], the paper boats [9], the tunnel [2]) and seven shrines (the hermit cell [10], the graveyard [8], the battlement [7], the tea party [6], the bombed building [5], the capsized boat [4], the broken eggs [3]), in total ten installation spaces. In Figure 7 the audio files are represented as paper boats, and the installations as symbolic images, numbered here for reference (for a detailed discussion of the installation see Author 1, 2019). 


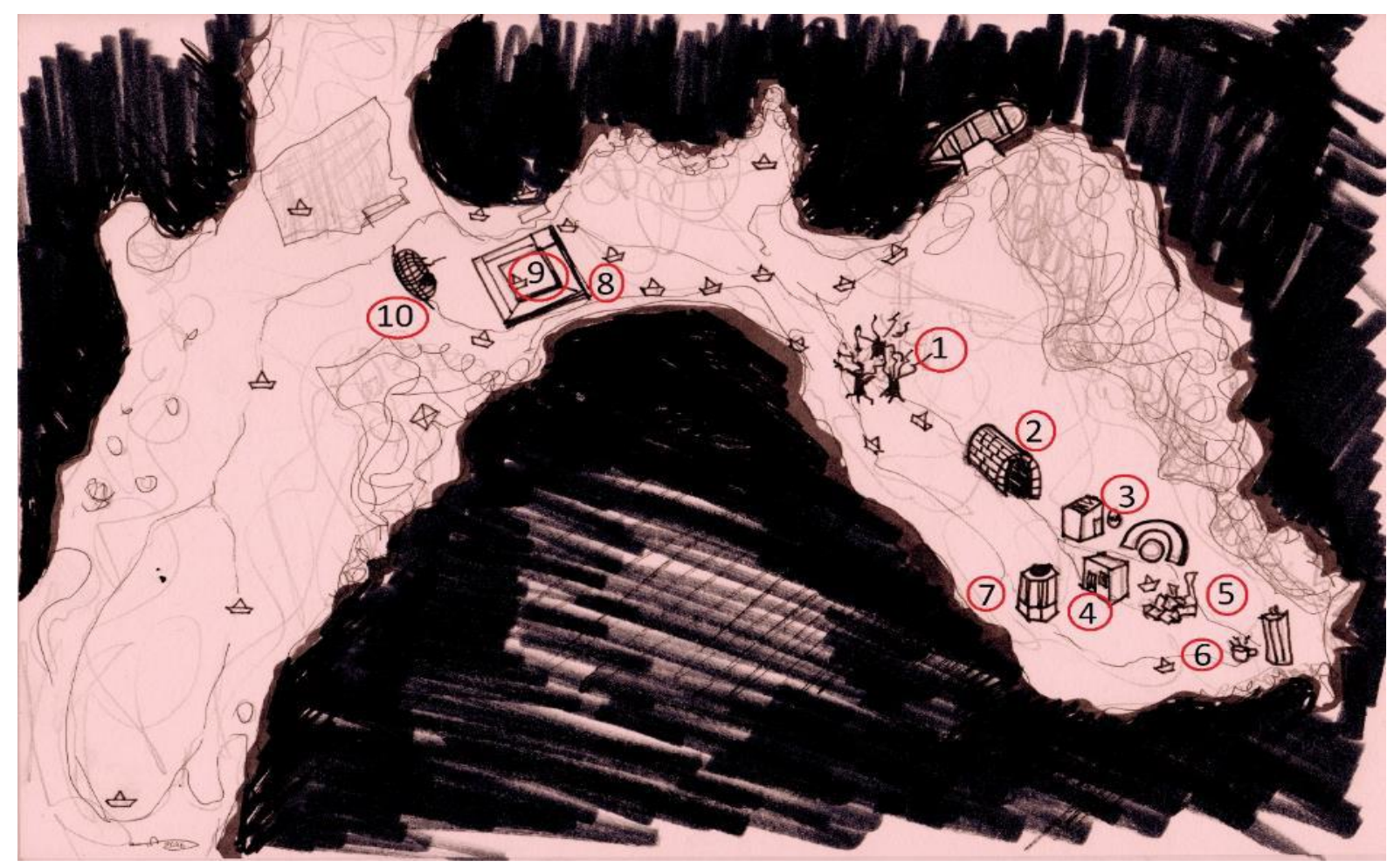

Figure 7 Inchcolm Project map numbered for convenience

Inchcolm island is an evocative space, it raises genre specific expectations, and summons all the island spaces, real or fictional, that the audience/players have previously experienced. They walked around the island and discovered audio and visual cues which 'fed' their process of meaning making. Walking transformed them into protagonists of their own story. The environment also contained embedded narratives: it is the character's memory palace, his subconscious guilt and repressed memories 'bleeding' over the natural environment. And finally, the designed environment stimulated the emergence of personal narratives. This are prompted by the designed environment but not envisioned necessarily by the designer, part design, part audience/player (see Alston's discussion of "errant immersion", 2016, or Calleja's 'alterbiography', 2011). The designed spaces and Inchcolm island ('ghost' and 'host', Pearson, 2010) worked together to support those evocative, enacted, embedded and emergent narratives. Sometimes the relationship was conflictual as they competed for primacy whereas other times it was harmonious as they complemented and emphasised each other. Catherine Turner observed that site-specific work turns the site and the work into co-creators (2004: 382) which write over each other creating a palimpsest. This complex palimpsest constantly engaged the audience/players' conscious attention in a deliberate act of performing, reading, listening, and watching the dance between the environments.

Inchcolm Project brought together the real and the virtual worlds and bodies, the two environments overlapped at times but also existed independently, adjacent to one another. The audience/players journeyed from Dear Rachel to Dear Esther and back again through mixed reality environments. This journey required that there were enough designed elements of continuity to ensure that the two realities did not feel disjointed. The text was designed to bridge between the two worlds: the text of Dear Rachel evoked Dear Esther and, in turn, was evoked during the Dear Esther gameplay. 
In Inchcolm Project the theme grew out of Inchcolm island's founding legend, the visual symbols of refuge constantly bringing the story to Inchcolm. At the same time, the moments of adapted environmental details linked Dear Esther to Inchcolm: the paper boats, the candles, the feathers, eggs and bird nests. The environmental design of Inchcolm Project was simultaneously game and site-responsive.

The text was the result of repeated playthroughs of Dear Esther, research into Inchcolm island, and refugee crisis stories and imagery. Inchcolm's histories, tales, legends and superstitions 'infiltrated' the text just as the writing style of Dear Esther did. Inchcolm's symbolic significance, as a place for meditation and ritual, as a refuge for those who seek salvation was also foregrounded. The theme of refuge echoed the larger social context in which we first played the game: the Syrian refugee crisis unfolding on the islands in the Mediterranean. We wanted to anchor the performance to these realities, transforming Dear Esther's theme of individual loss and grief into a societal one. Coping with loss and guilt connects the two stories, albeit at different levels. The story in Dear Rachel responds to the game's themes: dealing with guilt and loss, forgiveness and redemption while at the same time engaging with the wider ongoing debates surrounding refuge, safety and humanity. The man in Dear Esther is coping with the loss of his partner, Esther, to a tragic accident that he feels responsible for. The man in Dear Rachel is tormented by the images of a capsized boat, of a mother and her infant child sinking under the weight of counterfeit life jackets.

The writing process started with breaking down the text in Dear Esther. $\mathrm{I}^{2}$ wrote down phrases and words that were either repeated obsessively or created powerful and memorable images (Figure 8). Some of them later became leitmotivs in Dear Rachel: the hermit, refuge, salvation, gulls, ghosts, pestilence, death, salt, boat without a bottom. In writing the Dear Rachel text I worked with a set of creative constraints. Firstly, I wanted to write in a poetic and epistolary style that mirrors the rhythm, style and ambiguity of the narration in Dear Esther while in the same time to write in the text the island's legends and history. I also aimed when possible to write on the island, responding to and referencing its environments, locations, sounds, smells, tastes, and textures. The fragments were written for their intended locations, conveying some of my emotional responses to them as well as referencing visual, auditory, olfactory or tactile stimuli. Finally, I wanted to use repetition to reinforce important information - to use phrases as refrains thus ensuring that all audience/players will listen and remember them.

\footnotetext{
${ }^{2}$ The ' $\mathrm{l}$ ' in this section refers to [Author 1] henceforth, as the writer of the Dear Rachel.
} 


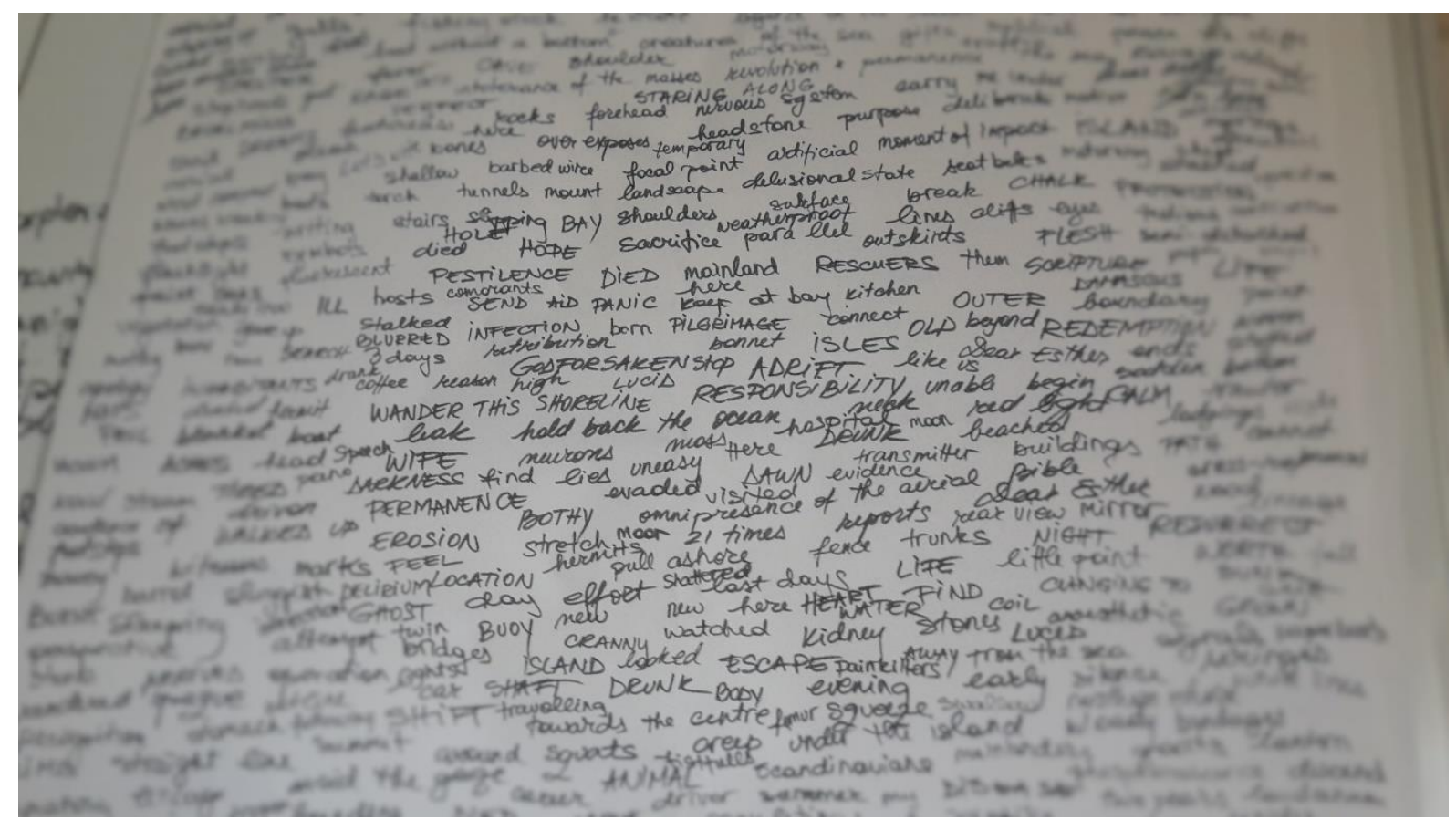

Figure 8 Deconstructing the text of Dear Esther

The text of Dear Esther conjures images which can be thematically grouped to communicate states or feelings and suggest certain interpretative pathways. We would argue that these images could be grouped in eight categories: geographical/geological and meteorological, physiological and medical, botanical and zoological, religious/moral, architectural, maritime, mechanical/relating to automobiles, communicational (see Table 4). Pinchbeck moves between them to create cross-category associations which act as metaphors. These are repeated obsessively, the leitmotivs of the text which gradually build the overarching themes and symbols of the game: guilt, forgiveness and redemption, salvation, flight, broken communication, fever dream/nightmare/hallucinations, island as purgatory, island as an extension/projection of the protagonist's body and mind, obsessive repetition in a desperate search for meaning, trauma and the fragility of the human mind. This obsessive repetition of words is mirrored by the repetition of musical motifs, environmental details, unlocked through the rhythmic and repetitive ritual of walking.

\section{Categories of images in Dear Esther and their textual referents}

Geographical/geological/meteorological $\quad$ island, outer isles, Wolverhampton, Sandford, M5, Welcome Break services, Bristol, Exeter, Oban, Cromer, wind, sea, sand, waves, ocean, caves, water, stone, cliffs, rocks, moon, beach, shoreline, bay, geography, geology, tides, thwart 


\begin{tabular}{|c|c|}
\hline Physiological and medical & $\begin{array}{l}\text { the mouth, the belly, the eye, kidney- } \\
\text { stone, birthmark, lips, wrist, arm, ankles, } \\
\text { chest, shoulders, death/dying, illness, } \\
\text { pestilence, infection, flesh, syphilis, } \\
\text { painkillers, bones, guts, operation, } \\
\text { bypass, veins, bruises, sick/sickness, } \\
\text { hips, ribcage, teeth, heart, fingernails, } \\
\text { forehead, nervous system, cuts, life, } \\
\text { birth, skin, femur, pain, tears, lucid }\end{array}$ \\
\hline Botanical and zoological & $\begin{array}{l}\text { grasses, seagulls, feathers, gulls, } \\
\text { goats, flowers, eggs, nests, bacteria, } \\
\text { sheep }\end{array}$ \\
\hline Religious/moral & $\begin{array}{l}\text { the hermit, transcendence, shepherds, } \\
\text { Damascus, water, sacrifice, rescue, } \\
\text { Godfearing, godforsaken, scripture, } \\
\text { charnel house, redemption, pilgrimage, } \\
\text { Bible, responsibility, redemption, } \\
\text { retribution, candles, headstone, torch, } \\
\text { Mercy seat, Paul, ascent, rebirth, Lot, } \\
\text { Lot's wife, dream, descent }\end{array}$ \\
\hline Architectural & $\begin{array}{l}\text { bothy, tunnels, cave, tarmac, road, } \\
\text { junction, motorway, museum, goat } \\
\text { shed, hospital, chimney, crematorium }\end{array}$ \\
\hline Mechanical/relating to automobiles & $\begin{array}{l}\text { hatchback, jump leads, ashtray, } \\
\text { combustion engine, windscreen, rear- } \\
\text { view mirror, glove compartment, brake } \\
\text { fluid, dented bonnet, seatbelts, crash, } \\
\text { wreck/wreckage, headlights, swerve, } \\
\text { moment of impact, tarmac, boot, tires, } \\
\text { wheel, skid marks }\end{array}$ \\
\hline Maritime & $\begin{array}{l}\text { salt, seagulls, boat, ship, boat without } \\
\text { a bottom, sea, shipwreck, sea } \\
\text { creatures, deep, surface, shore, } \\
\text { vapour trails, shoreline, cargo, wash } \\
\text { out, ocean, tides, buoy, lighthouse, } \\
\text { island, adrift, float, armada }\end{array}$ \\
\hline Communication & $\begin{array}{l}\text { radio, radio mast, beacon, aerial, } \\
\text { transmission, transmitter, message, } \\
\text { letter }\end{array}$ \\
\hline
\end{tabular}


I used a style of constructing metaphors inspired by Dear Esther, where the traumatic event and the human body become intermingled. Like Dear Esther, the intended function of these types of structures was to communicate that the poetic imagery hides an unnatural and painful event which has been repressed and is piercing through the subconscious. The obsessive repetition of words and phrases was also used to this effect.

Because I wanted to foreground the interpretive abilities of the audience/players, the text was intentionally ambiguous and fragmented in 20 'pieces' which were scattered around the island. This challenged me to write the text in such a way (I opted for poems) that it could be experienced in any order, and in any quantity, meaning that the number of 'pieces' found should not necessarily impact on the interpretation. The lyrical form of writing supported the open and ambiguous narrative, as well as the episodic nature of its reception.

The text also responded to the form of mediation, namely I developed a confessional tone of address: the text is written in the first person to suit the intimacy of the headphones.

Being a loosely adapted text, Dear Rachel was a constant negotiation between the source text and the potential text (Hutcheon and O'Flynn, 2012). This potential text was equally shaped by the site: its symbolic potential added another dramaturgical layer to the narrative, its stories and histories were embodied by its environment, and its physical appearance constantly shaped the structure of the text. These three functions of the site (as symbol, as structure, as storyteller, Wilkie, 2002) shaped the text by 'guiding' its reception (where the text is experienced), by shaping its themes (the text was site-responsive), and by aiding its semiotic and sensory interpretation (the symbolism of the island as refuge and prison eventually grew into the theme of the performance).

The sound was designed to mirror the multi-layered texture of Dear Esther's soundscape: music, diegetic sounds and the acousmatic male I-voice (Chion, 1999) speaking in the ear. The I-voice speaks in the present tense which contributes to the sense of conviviality but also coexistence, the audience/players and the voice are here together: "the walking partner may not be physically embodied, but is acoustically present through spoken words of a guide or guides, and it is significant to the sense of conviviality that they speak in the present tense" (Myers, 2010: 63). Using the I-voice facilitated what Myers calls "the sensation of a conversation" that audio guided walks can create: "With the use of a voice or voices guiding a walker, the sensation of a conversation is created through various strategies of narrative voice and rhythmic structuring of pace and path." (2010: 60). The audience/players become witnesses by merging their own experiences, narratives, memories and feelings with the ones heard in their ear (see Miller quoted in Myers, 2010: 62 ). This conversation becomes literal when two or more people are listening to the voice together, sharing "earpoints" (Myers, 2010).

Music was added in specific sound files to support the emotional tone of the voice and give a sense of emotional progression within each individual file. The music that we used was Curry's piece Always because I wanted to keep Esther's voice, and to introduce a musical theme that runs throughout the performance, while at the same time keeping the haunting quality of the female voice which stays with the narrator. I refer to it as haunting rather than a conversational quality because they never belong to the same 'place', the two types of voices have a different materiality, they 'come' from different places. The singing female voice exerts power over the male voice as it erupts and interrupts at will. 
We also decided to have musicians performing on the island (Figure 9) which introduced a layer of diegetic music to the soundscape. This created interesting overlaps between the different types of acoustic environments, mediated and unmediated, fictional and environmental. The instrumental solos were musical puzzle pieces of sorts which were assembled in the final musical performance. This created an overarching musical theme which could be traced throughout the Inchcolm Project experience (during the performance, in the game during the projection, and in the musical performance).
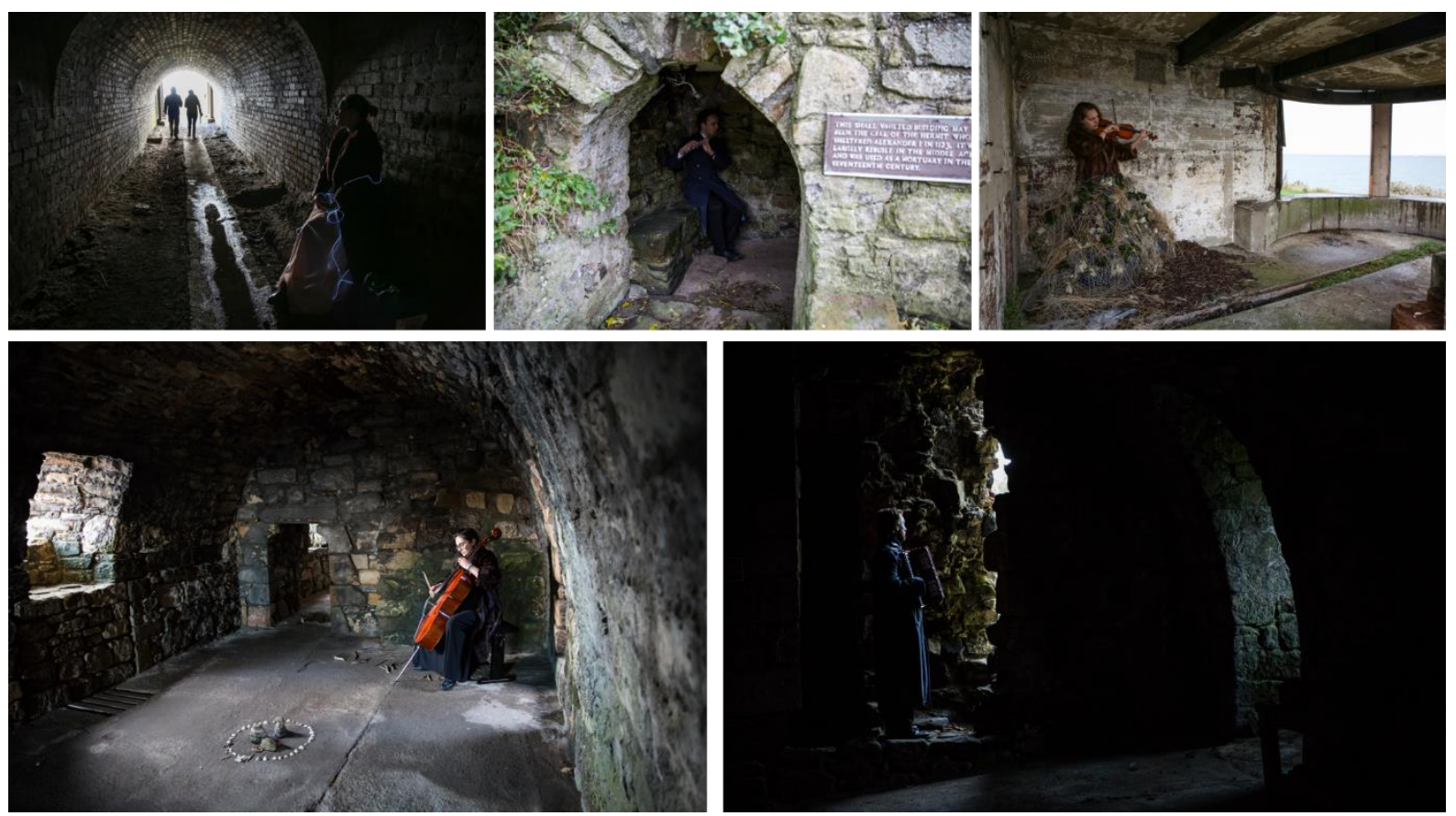

Figure 9 Musicians in Inchcolm Project

The positions of the audio files and musicians was carefully selected so as to facilitate a diverse and sensory-rich walk, thus contributing not only to the narrative but also to the interaction layer. By using static at the beginning and end of transmission, we created an opportunity for the audience/players to settle into an active listening mode. When the static started, they could stop to listen or keep on walking as long as they did so within the perimeter of the tagged area, reinforcing the connections between sound and movement.

We also used sound to focus attention to the environment by amplifying it. The static framed the audio signalling that what the audience/players were hearing was a fragment, a trace that somehow still lingered in the environment. Together, the audio files created a "sonic ruin" (Myers, 2010: 66), an eclectic composition of sound textures, rhythms and surfaces, "narrative debris drifting on radio waves" (ibid.). In Inchcolm Project the ruined landscape is mirrored in the 'ruined' soundscape, their fragmented, open and broken nature requiring interpretative effort, asking the audience/players to 'fill in the gaps': "the work encourages multiple readings and understandings through the soundscape's fragmented, repeated, looped and discontinuous narratives and invites similar choreographies of walking. In this way, walking the work is appropriately like walking through a ruin" (ibid.: 66). 
Most of the audio files were tagged in locations that facilitated encounters, offered vantage points, or emphasized landmarks or sensory information which was referenced in the text. The latter created the synaesthesia that Myers refers to, facilitating an embodiment of the narrative, an anchoring of the story in the lived experiential moment. In these moments the information is no longer abstract but personally meaningful, "embodied and more imaginatively and emotionally resonant" (Myers, 2010: 61).

Stopping, walking, standing and listening are woven together, creating a rhythm of the lived experience of Inchcolm Project. In both Dear Esther and Dear Rachel walking is the main form of interaction with the designed story world. In Inchcolm Project walking fulfils an aesthetic and a dramaturgical function. Aesthetic in that the walk was a performance, a series of encounters with sound files, installations, environments (landscapes, vistas) and other audience/players assembled through walking. Dramaturgical, in that the process of meaning making is enabled and performed by the moving body, making-sense and sensemaking (Machon, 2009), not just a cognitive activity but also a sensory one.

Walking can be simultaneously immersive and critical, the two stances alternating in the rhythms of walking: "The rhythms of walking allow for a particular experiential flow of successive moments of detachment and attachment, physical immersion and mental wandering, memory, recognition and strangeness" (Edensor, 2010: 70). By alternating between them the rhythm of walking allows for reconciliations and coexistences of different timeframes, spaces and critical distances.

In Inchcolm Project we intended to design opportunities for walking, either alone or with others. The environment, the narrative and the sound were designed to be experienced and interacted with through walking, offering the motivation for it. They enabled different rhythms of walking, exposing the moving body to the stories, textures, sounds, smells and sea- and landscapes of Inchcolm.

Technology also played a part, as groups sometimes shared phones, the phone and the length of the cable limiting their movement and speed, turning progression into a negotiation with the technology, with the other(s) and with the terrain (Figure 10). 

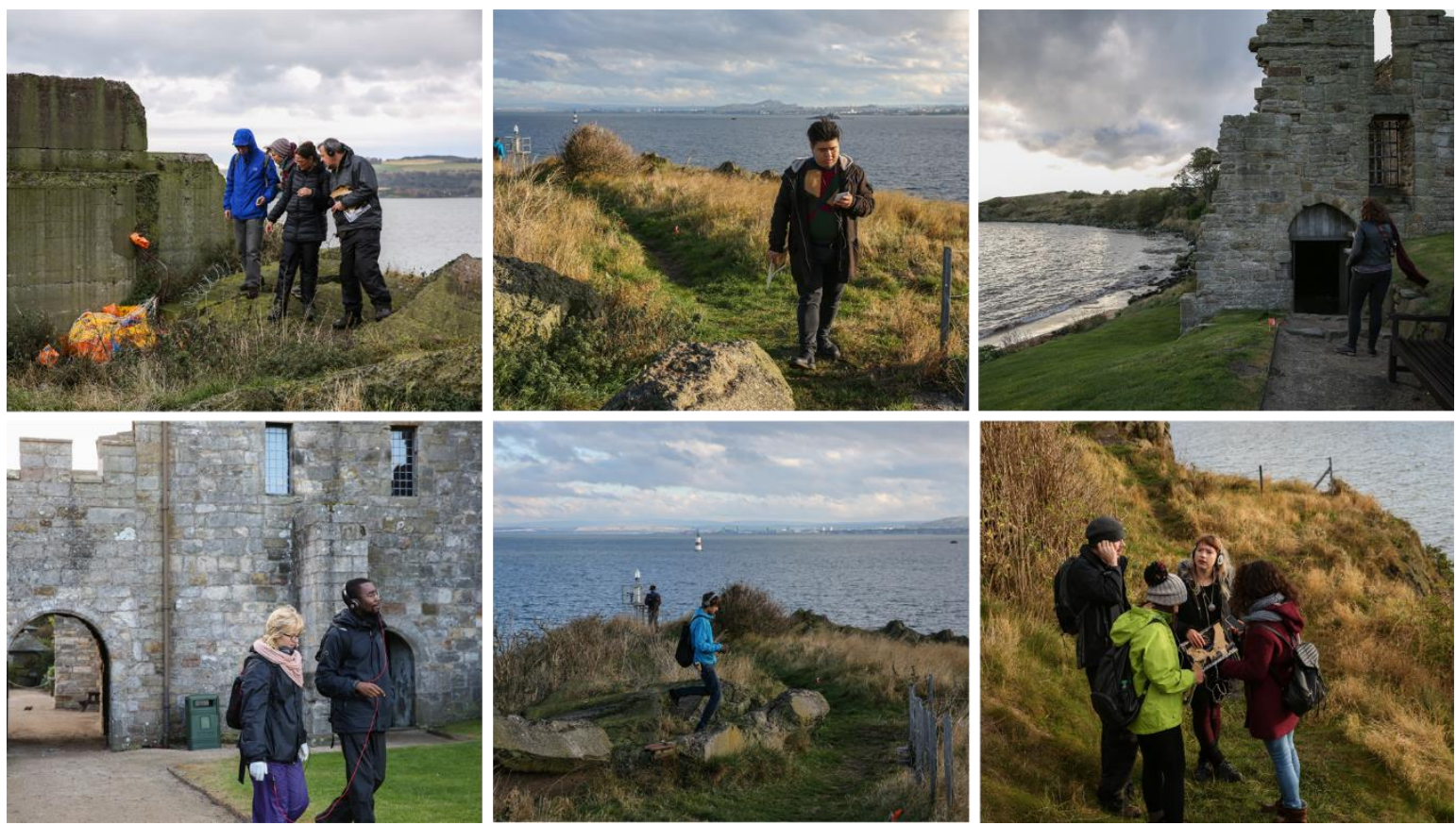

Figure 10 Audience/players walking and listening on Inchcolm

The development process of Inchcolm Project required a parallel process of dramaturgy through which the overall themes were developed at a macro (across all components of the project: performance, projection, musical performance) and micro level (narrative, environment, sound, interaction). This involved two types of processes: 'pruning' or removing everything which could offset the meaning-making process and devising, an improvisational type of assemblage. This process of dramaturgy ensured that the twooverall aesthetics, the palimpsest and (syn)aesthetics, were coherent and consistent throughout.

The aesthetic of the palimpsest is present in the making of the work and in its subsequent reception as both reading and (re)writing whereas (syn)aesthetics refers to the potential of creating and experiencing "interdisciplinary, intertextual and 'intersensual' work" which supports complex processes of sensory and semiotic meaning-making (Machon, 2009: 14). The three strata of Inchcolm Project (text, adaptation, and their respective mediums), their components, and the relationship of inter-dependency between were shaped through this dramaturgical process. All of these design strategies and techniques underpinned the development process of Inchcolm Project. Together they form a working method that we have called storywalking.

\section{Storywalking - a design framework}

Storywalking was developed and refined in the process of creating and critically reflecting on Inchcolm Project, a piece of work which is hybrid in its structure (with mixed-media and mixed-reality components) and inter-disciplinary in its design (video game design and sitespecific performance practice). Performance/participation, site, and audience/players are the three main components of storywalking and the heart of the process of creating 
Inchcolm Project. Storywalking facilitates the staging together of performance and video games by focusing on the moving body's search for meaning across/through virtual and physical spaces alike. Inchcolm Project's narrative arc was developed as a storywalk, a story which is performed by the walking body of audience/players as they assemble the narrative elements designed in the performance and the video game.

In Inchcolm Project we explored various narrative, spatial and temporal configurations with the aim of facilitating an experience continuum for the audience/player: they journey through both physical and virtual environments in search of meaning. Storywalking facilitates a search for meaning (assembling narrative 'puzzle' pieces) performed by the walking body of the audience/players as they journey through complex, sensory and storyrich environments, both physical and digital. These environments are layered (the aesthetic of the palimpsest) and incomplete (the aesthetic of the ruin) thus inviting the audience/player to complete the work by adopting different modes of engagement in the process of making-meaning: reading, writing, walking, playing, sensing and interpreting. Exploration becomes a dramaturgical device of assemblage which operates at two levels: of production, in the process of designing for the moving body and all its senses, and of reception in the process of performing the work.

In Inchcolm Project the adapted 'text' and the 'original' text were staged together, in close spatial-temporal proximity. The two stories shed light on one each other, made sense through one another. This was only possible because we designed moments of overlap, continuity and familiarity between the two islands (by re-creating and adapting sounds and images from Dear Esther in Dear Rachel) and moments of 'contagion' where Inchcolm's sensory information attached itself to the gameplay experience (during the gameplay projection). This is one consequence of the intrinsic liminality of hybrid spaces, as Giannachi notes:

Because the hypersurface is a liminal space, the viewer can double their presence and be in both the real and the virtual environment simultaneously. In other words, the viewer may be part of both the realm of image and the sphere of the real, and may modify one through the other (2004: 95).

If the hypersurface has such powers then storywalking might be a way of 'attaching' longelusive sensory information to gameplay (smell, taste, temperature). Storywalking embraces these 'bleedings' and 'slippages' of meaning (sense-making and making-sense) between the virtual and the physical bodies and environments. Throughout Inchcolm Project we tried to capitalize on these fuzzy areas where the virtual and the lived merge, and where the fictional world bleeds into the 'real' world.

Drawing from site-specific performance and game design, storywalking combines walking as an aesthetic, critical, and dramaturgical practice of reading and performing an environment, with designing interactive, complex, sensory and story-rich environments for a moving, meaning-making body. Our approach to environmental storytelling was developed during Inchcolm Project and drew equally from site-specific performance - where site is considered as a palimpsest (Turner, 2004) which illustrates the complex relationship between the designed ('ghost') and found/natural elements ('host') (Pearson, 2010) - and game design (particularly the design of Dear Esther). Site acted as storyteller, symbol, and structure (Wilkie, 2002), and becomes an active component "in the creation of performative meaning, 
rather than a neutral space of exposition" (Pearson, 2010: 36). In storywalking, the site is a central part of the experience as it adds a sensory, symbolic, narrative and structural dimension to it. In turn the storywalk reconfigures how the site is engaged with and can emphasise and focus attention on certain aspects of the site which might have been overlooked due to familiarity, speed of movement or destination and time constraints.

\section{Conclusion}

Through storywalking we explored how we could apply some of the design lessons learned from Dear Esther in performance, particularly ambiguity in design and storytelling (Pinchbeck, 2012a), symbolic environment design, creating emotional landscapes through dramatic visual style, use of detail for sewing the narrative to the world, subliminal signposting (Briscoe, 2012a), embedded and emergent storytelling, non-linearity (see Rouse III, 2001), anticipatory and interpretive play (Upton, 2015), anticipatory design (Rouse III, 2001). At the same time, we were 'listening' to the site and exploring design strategies and techniques used in participatory and site-specific performance, namely responding to the site as 'host' by creating narrative and sensory 'see-through' overlays - work as 'ghost' (Pearson, 2010: 35), using site and work as co-creators which combine to create a palimpsestic aesthetic (Turner, 2004), engaging with walking as an aesthetic practice through walkscapes (Careri, 2017), smell-walks (Henshaw, 2014), smellscapes (Drobnick, 2002; 2005; Hill and Paris, 2014; Howes, 2005; Porteous, 1985), seascapes (Pungetti, 2012), using sound to augment/complement/highlight the site - soundscapes (Murray Schafer, 1994; Smalley, 2007; Voegelin, 2014), in-situ creative writing, sound and visual installation design, exploring the aesthetic and narrative potential of the 'ruin' (Arnold-De Simine, 2015; Beswick, 2015; Dillon, 2011; Edensor, 2008; Lorimer and Murray, 2015; Smith, 2015).

The performance, the place and the moving body of the audience are in a symbiotic, semiotic-sensory relationship, what was previously discussed as (syn)aesthetics. This complex relationship between audience, place and performance and the associated processes of making sense and meaning through movement in multi-reality and hybrid environments is the central aesthetic of storywalking. Storywalking distils our approach to adaptation when adaptation entails remediation and interdisciplinary translation, and reconciles the two adaptation challenges which arise in practice: responding to the site, and to the game.

We are hopeful that storywalking will make its contribution to both contemporary performance practice and game design by providing new ways of designing and thinking about the design process. We also hope that this (syn)aesthetic approach to walking simulators will contribute to their understanding and appreciation as complex and layered experiences.

The term storywalking seemed apt in foregrounding the richness of walking as simultaneously discovering, living, performing, making, feeling, listening, remembering, playing and telling a story and an environment. It supports hybrid forms which can attract new audiences to video games and performance by providing multiple routes into the story. It can expand and diversify the scope of both fields to consider each other as potential 
platforms for expression and develop new forms of designing and presenting work in both fields. And finally, it can challenge the way we think about experience on a mixed-reality continuum by showcasing the potential of the body to experience and engage with both virtual and physical environments, their sensory-scapes and stories.

\section{Referenced Works}

Alston, Adam (2016) 'Making Mistakes in Immersive Theatre: Spectatorship and Errant Immersion', Journal of Contemporary Drama in English, 4(1). doi: 10.1515/jcde-2016-0006.

Arnold-de Simine, Silke (2015) 'The Ruin as Memorial - The Memorial as Ruin', Performance Research, 20(3), pp. 94-102. doi: 10.1080/13528165.2015.1049040.

Author 1 (2016) Dear Rachel - Performance score. Available at: https://www.performingplay.co.uk/text (Accessed: 31 $1^{\text {st }}$ August 2019)

Author 1 (2019) Playing with performance/performing play: creating hybrid experiences at the fringes of video games and performance. PhD Thesis. Abertay University. Available at: https://rke.abertay.ac.uk/en/studentTheses/playing-with-performanceperforming-play (Accessed: $31^{\text {st }}$ August 2019)

Bassett, Keith (2004) 'Walking as an Aesthetic Practice and a Critical Tool: Some Psychogeographic Experiments', Journal of Geography in Higher Education, 28(3), pp. 397410, doi: $10.1080 / 0309826042000286965$

Beswick, Katie (2015) 'Ruin Lust and the Council Estate', Performance Research, 20(3), pp. 29-38. doi: 10.1080/13528165.2015.1049034.

Bozdog, Mona and Galloway, Dayna (2019) 'Worlds at our fingertips: reading (in) What Remains of Edith Finch'. Games and Culture. https://doi.org/10.1177/1555412019844631

Briscoe, Robert (2012a) 'The Art of Dear Esther: Building an Environment to Tell a Story', Game Developers Conference, San Francisco [recorded conference talk]. Available at: https://www.gdcvault.com/play/1015839/The-Art-of-Dear-Esther (Accessed: 31st August 2019).

Briscoe, Robert (2012b) 'Up Close with Dear Esther Level-Designer Robert Briscoe'. Interview with Robert Briscoe. Interviewed by Zohra Ashpari for PC World, 8 March. Available at: https://www.pcworld.com/article/251408/up_close_with_dear_esther level designer rob ert briscoe.html (Accessed: 31st August 2019).

Calleja, Gordon (2011) In-game from immersion to incorporation. Cambridge, MA: MIT Press.

Careri, Francesco (2017 [2002]) Walkscapes: walking as an aesthetic practice. Ames, IA: Culicidae Press.

Chion, Michel (1999) The voice in cinema. Chichester: Columbia University Press.

Curry, Jessica (2013) 'The Music of Dear Esther: Creating Powerful Scores with Limited Resources', Game Developers Conference, San Francisco [recorded conference talk]. Available at: https://www.gdcvault.com/play/1017704/The-Music-of-Dear-Esther (Accessed: 31st August 2019).

Cyan, Inc. (1993) Myst - Microsoft Windows [video game], Brøderbund. 
Dillon, Brian (2011) Ruins. London: MIT Press/Whitechapel Documents of Contemporary Art. Drobnick, Jim (2002) 'Toposmia: Art, Scent, and Interrogations of Spatiality', Angelaki, 7(1), pp. 31-47, doi: 10.1080/09697250220142047.

Drobnick, Jim (2005) 'Volatile Effects: Olfactory Dimensions of Art and Architecture' in Howes, D. (ed.) Empire of the senses. Oxford: Berg, pp. 265-280.

Edensor, Tim (2008) 'Walking Through Ruins', in Ingold, T. and Lee Vergunst, J. (eds.) Ways of Walking. Ethnography and Practice on Foot. Farnham: Ashgate Publishing, Ltd, pp. 123142.

Giannachi, Gabriella (2004) Virtual theatres: An introduction. London: Routledge.

Heddon, Deirdre (2012) 'Turning 40: 40 Turns: Walking and friendship', Performance Research, 17(2), pp. 67-75. doi: 10.1080/13528165.2012.671075.

Henshaw, Victoria (2014) Urban Smellscapes: Understanding and Designing City Smell Environments. London and New York: Routledge.

Hill, Leslie and Paris, Helen (2014) Performing Proximity. Curious Intimacies. Basingstoke: Palgrave Macmillan.

Howes, David (ed.) (2005) Empire of the senses. Oxford: Berg.

Hutcheon, Linda and O'Flynn, Siobhan (2012) A Theory of Adaptation. 2nd edn. Abingdon: Routledge.

Inchcolm Project - performance. Available at: https://www.performingplay.co.uk/inchcolmproject (Accessed: $31^{\text {st }}$ August 2019)

Ingold, Tim (2016) Lines: A brief history. Routledge Classics edn. Abingdon, Routledge.

Ingold, Tim and Lee Vergunst, Jo (2008) Ways of walking: Ethnography and practice on foot. Farnham: Ashgate Publishing, Ltd.

Kagen, Melissa (2017). Walking Simulators, \#GamerGate, and the Gender of Wandering. In J. Eburne, \& B. Schreier (Eds.), Nerds, Wonks, and Neocons (pp. 249-274). (The Year's Work). Bloomington, Indiana: Indiana University Press.

Kagen, Melissa (2018). Walking, talking and playing with masculinities in Firewatch. Game Studies, 18. Retrieved February 21, 2019, from http://gamestudies.org/1802/articles/kagen Lorimer, Hayden and Murray, Simon (2015) 'The Ruin in Question', Performance Research, 20(3), pp. 58-66. doi: 10.1080/13528165.2015.1049037.

Machon, Josephine (2009) (Syn)aesthetics: Redefining visceral performance. Basingstoke: Palgrave Macmillan.

Machon, Josephine (2013) Immersive theatres: intimacy and immediacy in contemporary performance. Basingstoke: Palgrave Macmillan.

Murray Schafer, Raymond (1994) The soundscape: our sonic environment and the tuning of the world. Rochester, Vt.: Destiny Books.

Myers, Misha (2010) 'Walk with me, talk with me': the art of conversive wayfinding', Visual Studies, 25(1), pp. 59-68. doi: 10.1080/14725861003606894.

Pearson, Mike (2010) Site-specific performance. Basingstoke: Palgrave MacMillan. 
Pinchbeck, Dan (2012a) 'Dear Esther: Making an Indie Success Out of an Experimental Mod', Game Developers Conference, San Francisco [recorded conference talk]. Available at:

https://www.gdcvault.com/play/1015529/Dear-Esther-Making-an-Indie (Accessed: 31st August 2019).

Pinchbeck, Dan (2012b) 'Ambiguity and Abstraction in Game Writing: Lessons from Dear Esther', Game Developers Conference Europe, Cologne, Germany [recorded conference talk]. Available at: https://www.gdcvault.com/play/1016695/Ambiguity-and-Abstraction-in-Game (Accessed: 31st August 2019).

Pinchbeck, Dan, Curry, Jessica and Briscoe, Robert (2017) 'Director's Commentary', Dear Esther Landmark Edition - Microsoft Windows [video game], The Chinese Room.

Porteous, J. Douglas (1985) 'Smellscape'. Progress in Physical Geography: Earth and Environment, 9(3), pp. 356-378. https://doi.org/10.1177/030913338500900303.

Pungetti, Gloria (2012) 'Islands, culture, landscape and seascape', Journal of Marine and Island Cultures, 1(2), pp. 51-54. Available at: https://doi.org/10.1016/i.imic.2012.11.007 (Accessed: 31st August 2019).

Rouse III, Richard (2001) Game Design - Theory and Practice: The Elements of Gameplay. Gamasutra, 27 June 2001. Available at:

https://www.gamasutra.com/view/feature/131472/game_design theory and practice.p hp (Accessed 31st August 2019)

Ruberg, Bonnie (2019) Video Games Have Always Been Queer. New York: NYU Press.

Smalley, Denis (2007) 'Space-form and the acousmatic image', Organised Sound; Org.Sound, 12(1), pp. 35-58. doi: 10.1017/S1355771807001665.

Smith, Phil (2015) 'Sites of Dereliction: Beginnings and allies of performance', Performance Research, 20(3), pp. 67-74. doi: 10.1080/13528165.2015.1049038.

Smith, Harvey and Worch, Matthias (2010) 'What Happened Here? Environmental Storytelling'. Game Developers Conference, San Francisco [talk slides]. Available at: https://www.gdcvault.com/play/1012647/What-Happened-Here-Environmental (Accessed: 31st August 2019).

Solnit, Rebecca (2002) Wanderlust: a history of walking. London: Verso.

The Chinese Room (2012) Dear Esther - Microsoft Windows [video game], The Chinese Room.

Turner, Cathy (2004) 'Palimpsest or Potential Space? Finding a Vocabulary for Site-Specific Performance', New Theatre Quarterly; New Theatre Quarterly, 20(4), pp. 373-390. doi: 10.1017/S0266464X04000259.

Upton, Brian (2015) The aesthetic of play. London; Cambridge, Mass.: MIT Press.

Voegelin, Salomé (2014) Sonic Possible Worlds. Hearing the Continuum of Sound. New York; London: Blomsbury Academic.

Wilkie, Fiona (2002) 'Mapping the terrain: a survey of site-specific performance in Britain', New Theatre Quarterly, 18(2), pp. 140-160. 